Александр Иваницкий

ORCID: 0000-0001-6644-7401

Российский государственный гуманитарный университет

Москва, Россия

\title{
Этика героя новелл Генриха фон Клейста (эволюция значений)
}

https://doi.org/10.34739/clit.2021.15.08

\section{Ethics of the Hero in the Novellas of Heinrich von Kleist (Evolution of the Meanings)}

\begin{abstract}
The key role of the ethics in the H. v. Kleist's novellas comes from the providential character of the life's unfolding. Having guessed it, the characters face the moral choice which needs to be implemented. The paradoxical uncovering of the providence as fate triggers the moral and behavioral "relay race" of characters, realizing the stages of this implementation. The historicism of the providence makes it to the dialectic of the world's transformation with the help of the character, who had intuitively guessed this dialectics. Meanwhile, history as the social movement of the people makes moral / behavioral "relay race" of characters the stages of this movement.
\end{abstract}

Keywords: providence, fate, moral choice, dialectic, history, novella, dramatic story

Моральная проблематика важна для понимания прозы Г.ф. Клейста в двух отношениях. Прежде всего - с современным ей немецким романтизмом, где моральный выбор героя задавало явное «сказочно-испытательное» волшебство. У Клейста же сам факт сверхъестественного вмешательства в жизненный ход, как правило, недостоверен. Поэтому герой интуитивно угадывает его смысл как Про-мысел и «завершает» его действие своим ${ }^{1}$. Это высвечивает «от

\footnotetext{
${ }^{1}$ Cм.: W. Hamacher, Das Beben der Darstellung, [in:] Positionen der Literaturwissenschaft: Acht Modellanalysen am Beispiel von Kleist "Das Erdbeben in Chili", Bearbeitet von David. E Wellbery. W. Hamacher, Muenchen 1985, S. 153-155; 161-162; cp.: K.-H. Maurer, Gerechtigkeit zwischen Differenz und Identitaet in Heinrich von Kleists "Michael Kohlhaas", "Deutsche Vierteljahrsschrift fur Literaturwiss. u. Geistesgeschichte” 2001, Jg. 75, Heft 1, S. 136.
} 
противного» принципы корневой для немецкого романтизма волшебно-сказочной фантастики².

Также моральная «психо-логика» клейстовской беллетристики проявляет ее межвременные связи. С одной стороны - преемство средневековому жанру «экземпла» 3 - чем-то вроде загадки, разгадка которой (вмешательство иномирных сил в земную жизнь) обнаруживалась в финальном моралите4. Возможно, именно благодаря этому преемству у Клейста в наивысшей мере проявился драматизм новеллы ${ }^{5}$. А с другой - отмечавшиеся у Клейста предвестия европейского экзистенциализма последующего столетия. Суммарно же она углубляет понимание роли писателя в развитии европейской малой прозы.

Европейская филология рассматривала этику Клейста через сюжетно-смысловую систематизацию как проявлений «Промысла», так и откликов героев на него. Наиболее полно - в Землетрясения в Чили, которому была посвящена коллективная монография, а также в Михаэле Кольхаасе, где вторжение высшей силы в лице ее вестника (гадалки) не исчерпывает сюжет, но встроено в него.

Однако не менее важен в этом плане анализ второго важнейшего морального мотиватора героев Клейста - Истории, являющейся, как известно «хронотопом» большинства его новеллистических сюжетов. И в частности, выделение у Клейста двух «типов» Истории: катастрофических потрясений либо необратимых перемен в судьбах народов. А также - описание взаимосвязи Истории и Промысла получающих признаки друг друга либо соподчиненных как целое и часть.

Многозначность «промысла» в непредсказуемо-катастрофическом и парадоксальном движении клейстовских фабул, с одной стороны, превращала рассказчика в почти безличного хроникера,

\footnotetext{
${ }^{2} \mathrm{O}$ совпадениях / несовпадениях прозы Клейста с немецким романтическим контекстом см., в частности: А.В. Михайлов, Вводная часть доклада "Генрих фон Клейст и проблемы романтизма" , [в:] А.В. Михайлов, Обратный перевод. Москва, 200о, с. 34-45; cp.: H.J. Kreutzer, "... aber niemand bedarf ihrer...", [in:] Holderlin-Jahrbuch, Band 26, 1989, S. 60-73.

3 Cм.: H.J. Schneider, Der Zusammensturz des Allgemeinen, [in:] Positionen der Literaturwissenschaft: Acht Modellanalysen am Beispiel von Kleist "Das Erdbeben in Chili", Bearbeitet von David. E Wellbery. H.J. Schneider, Muenchen 1985, S. 120-121; cp.: K.-H. Stierle, Das Beben des Bewusstseins / Die narrative Struktur von Kleists 'Das Erdbeben in Chili', [in:] Positionen der Literaturwissenschaft: Acht Modellanalysen am Beispiel von Kleist "Das Erdbeben in Chili", Bearbeitet von David. E Wellbery. K.-H. Stierle, Muenchen 1985, S. 57-58.

4 См.: А.Я. Гуревич, Культура и общество средневековой Европь глазами современников (Exетpla XIII века), Москва 1989, с. 7-9.

5 См.: Е.М. Мелетинский, Историческая поэтика новеллы, Москва 1990, с. 74, 148.
} 
а с другой - делала его одной из ипостасей суммарного образа автора. Автор, в отличие от рассказчика, способен угадать не только вмешательство Промысла, но его глубинную и последовательно проявляющуюся диалектику ${ }^{6}$. Ее у Клейста (прежде всего, Маркизе бон О. и Михаэле Кольхаасе) рождает историзм - во многом обусловленный духовной биографией писателя.

Прежде всего, это т. н. «кантовский кризис» на рубеже XVIII-XIX вв. Кантовскую непроницаемость вещи юный Клейст осознал как роковую иррациональность действительности. Это наделило личный моральный выбор экзистенциальным значением. Крах в 1806 г. «просвещенно-абсолютистской» Пруссии Фридриха II («Великого») (в свете неприятия Клейстом французской версии общественного договора, лишенного рыцарского и отсюда - национального духовного содержания7) наделил иррациональность мира в его глазах значениями парадоксального и исторического в своей основе промысла, чье внешнее проявление обратно внутреннему смыслу. Его можно и нужно улавливать во внешне неприметных частных обстоятельствах. Неслучайно именно прусский крах побудил Клейста перейти от драм к новеллам, а также к хроникерской журналистике, изданию журнала «Берлинские вечерние листки» ("Berliner Abendblaetter”, 1810-1811), где поиск «знамений промысла» воплотился в первую очередь в анекдотах, ставших не только идейной, но и морфологической основой для новелл ${ }^{8}$. В «этическом» контексте их можно разделить на два не хроно- но логически наследующих друг другу типа.

1.

В первом из них Промысел утверждает извечный моральноправовой порядок, который герою остается понять и принять в своем моральном выборе. Радикальный случай - пассивное принятие полного личностного «обнуления» как карающего блага в новелле Святая Цецилия, или Власть музыки (Die heilige Caecilie, oder Gewalt $\operatorname{der}$ Musik, 1810), наиболее близкой «экземпла». Монастырь в Аахене

\footnotetext{
6 Ibidem, c. 163-164, 168, 170; ср.: Н. Берковский, Романтизм в Германии, СанктПетербург 2001, с. 407-408; A. Stephens., Kleist - Sprache und Gewalt, 1 Auflage, Freiburg im Breisgau 1999, S. 291.

7 Cм.: F. Loch, Kleist, Leipzig 1978, S. 70-74, 78.

8 Об анекдоте, кратком сообщении об исключительном / парадоксальном происшествии как одном из жанровых источников новеллы см.: Е.М., Мелетинский, op. cit., с. 17-19; ср.: М.И. Бент, А.С. Пушикин и Г. фон Клейст: шесть фрагментов к сравнительной истории литературы, «Вестник Челябинского университета, Серия 2, Филология» 1999, № 1, с. 73.
} 
XVI в., обреченный погрому протестантов, спасается изумительным исполнением мессы, продирижированной престарелой монахиней и повергшей погромщиков ниц перед соборным алтарем. К утру выясняется, что монахиня, виденная всеми в церкви, в это время лежала в горячке, от которой тем же вечером скончалась. Это открывает послушницам и читателю, что за дирижерским пультом была сама патронесса музыки Святая Цецилия. При этом главные действующие лица, прибывшие из реформаторских Нидерландов четыре брата - погромщика, не просто остановлены в своем святотатстве, но пожизненно повержены в блаженное безумие.

В Локарнской нищенке (Das Bettelweib von Locarno) того же 1810 года, написанной в жанре «видения» (довлеющего «экземпла»), герой, осознавший свой грех, карает не только себя, но и весь «свой» мир, ставшего сценой этого греха. Заглавная героиня, попросившая приюта в замке близ альпийского Локарно, по приказу вернувшегося хозяина - маркиза перебирается за печку, по дороге спотыкается, повреждает крестец и к утру умирает. Затем в течение нескольких лет она является обитателям замка в виде привидения, под влиянием чего косвенно виновный в ее гибели маркиз сжигает себя вместе с замком.

В Поединке (Der Zweikampf, 1811) «Промысел» проявляет свое итоговое значение «от противного». Якоб Рыжебородый, оспаривающий власть в средневековой Богемии у сводного брата, герцога Вильгельма Брайзахского, убивает его из засады, а в качестве «алиби» представляет кольцо знатной дамы, Литтегарды фон Ауэрштайн, благосклонности которой он прежде безуспешно добивался и с которой якобы провел ночь убийства. При этом лжесвидетельствует он «искренне»: камеристка Литтегарды и бывшая любовница Якоба успешно попыталась вернуть его расположение, одевшись в платье своей хозяйки, похитив ее кольцо и в роковую ночь выдав ему себя за нее. Рыцарь, влюбленный в Литтегарду берется защитить ее честь перед клеветником в судебном поединке. Тот заканчивается, как будто бы, победой Якоба, нанесшего рыцарю серьезную рану и принудившего того к сдаче. Однако с течением времени рана побежденного затягивается, а легкая царапина победителя, наоборот, ведет к смертельному недугу. Перед близким концом Якоб узнает, кто был с ним в роковую ночь, и публично признается как в невольной клевете, так и в убийстве. Раскаяние преступника, как видим, предопределяет «трех-ступенчатое» действие «промысла» - официально признанное в финале судом в качестве правового прецедента: «...в статутах священного божественного 
поединка всюду, где высказывается предположение, что вина через него непосредственно обнаруживается, были вставлены слова: “Если такова воля Божия"»9. Эти «ступени» - любовный «маскарад», провоцирующий убийцу на «искреннюю ложь», - его мнимая победа в судебном поединке - «медицински - летальные» итоги последнего.

Героя новеллистической повести Найденыи (Der Findling, 1811 г., изд. в 1812) генуэзского купца Пьячи тот же «многоступенчатый» промысел побуждает последовательно осознать один и то же свой поступок благодеянием и грехом. Во время торговой поездки на Сицилию он оказывается в зачумленном городе, спасает умирающего сироту Николо и усыновляет его. Ребенок выздоравливает, но первой его жертвой оказывается заразившийся от него и умерший родной сын Пьячи. Впоследствии усыновленный предает своего благодетеля, пытается, по образцу мольеровского Тартюфа, сначала обольстить его молодую жену, а затем оболгать его самого в суде и завладеть его домом. Купец осознает, что чума - знамение нечистого, а приемыш не жертва заразы, а ее исчадие. Он убивает приемного сына; на суде отказывается объяснить причину и идет на костер без отпевания, чтобы, попав в преисподнюю, завершить расправу над ее посланником и этим искупить грех его спасения. Таким образом, промысел являет себя герою в форме «рока» (чумы и ее губительного посланца). А орудием промысла открывший его герой становится в парадоксальной, «отступнической» форме, следуя за грешником в его загробную область.

2.

Во втором типе новелл Клейста оксюморный «рок-промысел» уже не консервирует мир, а необратимо меняет его - подспудно, а затем и явно составляя содержание истории. В Землетрясении в Чили (Das Erdbeben in Chili, 1807), посвященном гибели Сант-Яго в 1647 г., Провидение, как и в Найденыше, заявляет себя в оболочке «рокового» природного катаклизма. Катаклизм этот, в свою очередь, продолжает свое (и, тем самым, «провиденциальное») действие в стихии социальной - погромах, перерастающих в разрушительный бунт против светской и религиозной власти (после того, как вицекороль погибает, обезумевшая от вседозволенности толпа разрушает дворец епископа и т. д.).

Если природная стихия, как будто бы, развенчивает католическую картину мира (через реминисцентно заданное

9 Немецкая романтическая повесть, Тт. 1-2, т. II, Ленинград 1935, с. 346. 
антикатолическое, просветительское восприятие Лиссабонского землетрясения 1755 г. в посвященной ему поэме Вольтера следующего 1756-го), то стихия толпы дезавуирует основывавшуюся на том же Просвещении французскую революцию 1789-1793 гг. ${ }^{10}$. Но совместно землетрясение и спровоцированный им бунт спасают и воссоединяют главных героев: монашку Хозефу, осужденную на публичную казнь за любовную связь в монастырских стенах, и ее возлюбленного Херонимо, готового из-за предстоящей казни любимой покончить с собой.

Их прибежищем (как и прочих спасшихся) становится загородная долина, предстающая местом новообретенного «золотого века» в его руссоистской «версии» всеобщего братства. Однако благодарность Богу за спасение и воссоединение вкупе с чувством невольной вины перед жертвами стихии, «оплатившими» их счастье своими жизнями ${ }^{11}$, побуждает влюбленных вернуться в город, в единственную сохранившуюся городскую церковь. Там толпа чинит над ними самосуд, под влиянием проповеди священника увидев в землетрясении Божью кару за их грех. Тем самым, землетрясение последовательно направляет толпу на разрушение традиционного католического порядка, а затем на его восстановление с помощью «искупительной» жертвы ${ }^{12}$.

Но то же «провидение» спасает от расправы Филиппа, плод незаконной любви беглецов. Жертвенной ценой спасения оказывается убитый по ошибке Хуан, сын дона Фернандо, тщетно пытавшегося защитить Херонимо и Жозефу от толпы и усыновившего Филиппа. В финале новеллы именно Фернандо осознает суммарный провиденциальный смысл происшедшего: «...когда дон Фернандо сравнивал Филиппа с Хуаном и думал о том, как он приобрел того и другого, ему почти казалось, что он должен радоваться тому, что случилось»13.

Этот итог опять-таки «рифмует» новеллу с Найденышем: чужой ребенок, усыновленный ценой гибели своего, знаменует уже не искушение преисподней, а небесное благо. Таким образом,

10 Cм.: Fr. Kittler, Ein Erdbeben in Chili und Preussen, [in:] Positionen der Literaturwissenschaft: Acht Modellanalysen am Beispiel von Kleist "Das Erdbeben in Chili", Bearbeitet von David. E Wellbery. Fr. Kittler, Muenchen 1985, 1985: 30; cp.: H.J. Schneider, Der Zusammensturz..., op. cit., S. 123-124.

${ }^{11}$ Cм.: K.-H. Stierle, Das Beben..., op. cit., S. 56-57, 63.

${ }^{12}$ Cм.: R. Girard, Mythos und Gegenmythos. Zu Kleists 'Das Erdbeben in Chili', [in:] Positionen der Literaturwissenschaft: Acht Modellanalysen am Beispiel von Kleist "Das Erdbeben in Chili", Bearbeitet von David. E Wellbery. R. Girard, Muenchen 1985, S. 143-144.

13 Немецкая романтическая повесть..., ор. cit., т. II, с. 238. 
в Землетрясении в Чили возникает моральная «эстафета»: различные стадии действия парадоксального промысла осознают герои, перенимающие друг у друга «эстафету» жизненную.

Герой Маркизы фон О... (Die Marquise von O..., 1808), изображающей эпизод итальянской войны России с наполеоновской Францией, осознает один и тот же поступок сначала чудовищным зло, а затем сужденным свыше благодеянием. Это выглядит инверсией духовного пути купца Пьячи в Найденыше. Механизмом же как Промысла, так и его осознания выступает в Маркизе... История, которая, как и в Землетрясении в Чили, проявляется в виде буйства толпы. Но здесь это буйство уже не сопутствует стихии, а заменяет ее ${ }^{14}$.

Новелла обыгрывает сюжет из Опытов М. Монтеня: женитьбы героя постфактум на женщине, лишенной им девственности в забытьи и забеременевшей от него. Ворвавшиеся в итальянскую крепость русские солдаты, распаленные битвой, пытаются обесчестить заглавную героиню, вдовствующую дочь коменданта крепости, вдохновляя своего командира, графа Ф., на ее рыцарское спасение. Но затем страсть подчиненных превращает загоревшуюся в графе любовь к упавшей в обморок маркизе как спасенной Прекрасной Даме в похоть по отношению к ней же как военной добыче. Эту метаморфозу косвенно проявляет шутка матери маркизы о том, что граф привык «...завоевывать женские сердца приступом, как крепости»15. Но ее «воинская» семантика предопределена тем, что и в рыцарском противостоянии собственным солдатам, и в дальнейшем почти безотчетном осуществлении их умысла графом управляет общая атмосфера битвы, итурма и овладения, воплощенная в коллективном действии и сознании вооруженной толпы.

Глубоко раскаиваясь в насилии над «Прекрасной Дамой», граф ищет искупительной смерти в боях и, думая, что нашел ее, произносит имя Юлии. Но смерть оказывается временной («инициационной») направляя оправившегося и духовно воскресшего графа на новую встречу с забеременевшей (но не ведающей, от кого) маркизой и побуждая к признанию в насилии и сватовству к ней. Маркиза сначала с гневом отвергает рыцаря - насильника как «дъявола», который «...при первом своем появлении ...представился ей ангелом» ${ }^{16}$, но

\footnotetext{
14 Cм.: D.E. Wellbery, Das Beben des Bewusstseins / Die narrative Struktur von Kleists 'Das Erdbeben in Chili, [in:] Positionen der Literaturwissenschaft: Acht Modellanalysen am Beispiel von Kleist "Das Erdbeben in Chili", Bearbeitet von David. E Wellbery. D.E. Wellbery, Muenchen 1985, S. 71-72.

${ }_{15}$ Немецкая романтическая повесть..., ор. cit., т. II, с. 190.

16 Ibidem, c. 221.
} 
затем принимает его, так как не только видит свою беременность «непорочной», но и ребенка - «Божьим даром» ${ }^{17}$.

Брак подтверждает угадывание героем происшедшего с ним как диалектики промысла. «Первобытно-воинское» нападение на маркизу пробудило в нем рыцарские стремления спасти «Прекрасную Даму». Спасение, однако, возвращает ему архаическое восприятие ее как воинского трофея. Это спасение, в свою очередь, переводит «рыцарство» графа в новое качество: раскаяния и самоотреченного искупления вины ${ }^{18}$. Этим граф «разворачивает» моральный путь антигероя Поединка. Свою «беззаконную» любовь он осознает не адским соблазном, а ступенью рыцарского служения. И соединяет душевную и моральную синтагматику Херонимо и Фернандо; его временная («инициационная») смерть снимает трагическижертвенную сюжетику Землетрясения.... Первопричиной же этого «креатива» выступает История.

В драматической повести Михаэль Кольхаас (Michael Kolchaas, начатой в 1804-м и принявшей окончательный облик в том же 1810 г.) История переходит в новое качество. Ее субъектом становится народ, а содержанием - необратимые (в перспективе!) социальные перемены - знамением которых и становится «непостижимое». Это наделяет новым содержанием народный бунт. В отличие от хайдельбергских и йенских романтиков, пруссак Клейст видел «осевым» немецким временем Реформацию XVI в. ${ }^{19}$, когда сформировавшееся бюргерство духовно объединяло Германию на новой, лютеранской основе. В ...Кольхаасе оно воплощено в судьбе заглавного героя, конного барышника, поднявшего бунт за свои права против феодального произвола (его коней, несправедливо задержанных в замке юнкера фон Тронка, едва не заморили на хозяйственных работах).

Внешне в основу «рока» ложится случай, упоминаемый рассказчиком в связи с каждым событием в жизни героя: «на беду», «как на грех» и т.п. Такие повторяющиеся случаи устойчиво

\footnotetext{
17 Это высвечивается возможной испанской католической символикой «О», которым зашифровано имя маркизы: «Madonna de la O» или «Maria de la O» означает «Мария в благой надежде». См. подробнее: St. Huff, Kleist and Expectant Virgins: The Meaning of 'O', in "Die Marquise von O...", "Journal of English and Germanic Philology", 1982, № 81, 3, Pp. 369-374.

18 O куртуазии неявно говорит и французский титул маркизы, а не немецкой маркграфини. В то же время приснившийся графу лебедь проявляет «синкретику» его чувств: символизируя чистоту, он в то же время отчетливо отсылает к фигуре Зевса, овладевшего Ледой в обличье лебедя.

19 См. об этом. напр.: R. Gaderer, "Michael Kohlhaas" (1808/10): Schriftverkehr - Burokratie Querulanz, „Zeittschrift fur deutsche Philologie” 2011, Band 130, Heft 4, S. 537-539.
} 
осознаются самим Кольхаасом как проклятие его жизни: «от знакомых советников $[\mathrm{oH}]$ получил подтверждение того, о чем ему сказало сердце...»; ср.: «Кольхаас весь месяц томился недобрыми предчувствиями - и как в воду глядел...»²0 и т. п.

Между тем, случай всякий раз осуществляет наибольшую социальную вероятность, вытекающую из сословного неравенства в феодальной Саксонии. Не выспавшийся кастелян юнкера фон Тронка требует от Кольхааса пропуск на проезд в Дрезден. «Как на грех», сам юнкер в момент прихода к нему Кольхааса бражничал с друзьями, что и побудило его поддержать произвол слуги, а не правоту барышника. Конюх Херзе, оставленный Кольхаасом при конях у Тронка, был избит и изгнан слугами за отказ отпустить их в работу на угодьях кастеляна. Иск Кольхааса о заморенных лошадях в Дрезденский суд отклоняется судьями, состоящими в родстве с Тронка, - как и тамошний канцлер Кальхайм. Супругу Кольхааса Лисбет, привезшую прошение мужа в Шверин и использующую прошлое сватовство к ней кастеляна Шверинского замка, стражник смертельно ранит копьем; бывший соратник Нагельшмидт, изгнанный Кольхаасом за мародерство незадолго до роспуска шайки, собирает ее заново и возобновляет разбой от имени Кольхааса, сидящего в Дрездене под домашним арестом.

Именно эта социальная логика, последовательно проявляющая себя в якобы «роковых случаях», меняет моральную позицию и поведение Кольхааса. Исходно он сосредоточен на судебной тяжбе, но гибель жены толкает его к мстительному бунту, который по собственной логике превращается в разбой как таковой.

Иррациональное правосудие, возвращающее Кольхаасу его откормленных коней, но казнящее его за поднятый мятеж, знаменует исторический тупик феодального общества и его права. Это задает новое, национально-историческое значение Промысла, переводящее германский мир в Новое время. Пророчество о нем, сделанное цыганкой - ворожеей и случайно попавшее к Кольхаасу, предвещает закат погубившей героя феодальной Саксонии и триумф Бранденбурга - будущей лютеранской просвещенно-абсолютистской Пруссии, чей примат общенационального (внесословного) патриотизма остановит, с точки зрения Клейста, феодально-бюргерское противостояние ${ }^{21}$.

\footnotetext{
${ }^{20}$ Г. ф. Клейст, Драмы. Новеллы, Москва 1969, с. 442-443, 452.

21 Об исторической перспективе, открываемой пророчеством цыганки, см.: F. Kосh, Heinrich von Kleist. Bewusstsein und Wirklichkeit, Stuttgart 1958, S. 278-280; cp.: Th. Wichmann, Heinrich von Kleist, Stuttgart 1988, S. 187.
} 
Тем самым, впервые у Клейста разводятся «рок» как маска разрушительной социальной статики и «Провидение» как воплощение сменяющей ее исторической динамики ${ }^{22}$. Это ведет к схожей с Землетрясением... моральной эстафете, становящейся теперь исторической: от Кольхааса - к бранденбургскому курфюрсту. Подспудно курфюрст сознает историзм происходящего и «жертвенную необходимость» правового / бунтарского пути Кольхааса, призванного «исчерпать» феодальное правосудие, чтобы дать возможность Бранденбургу исторически упразднить его. Поэтому он, подобно Фернандо, берет патронаж над детьми казнимого им же барышника, видя в них залог осуществления предначертанного историей. Историзм действия (осознание которого герой подтверждает и продолжает собственным действием) превращает новеллу в драматическую повесть.

$$
* * *
$$

Моральный выбор героев программных новелл Клейста диктуется Историей, устойчиво выступающей в обличье Промысла, но меняющей собственный смысл. Там, где История представляет собою потрясения в судьбах народов, Промысел восстанавливает извечную мораль, к которой герои возвращаются. Там, где История необратимо меняет жизнь народов, Промысел является героям формой либо знамением ее действия. Это рождает морально - поведенческую эстафету героев, чье последовательное угадывание смысла происходящего с ними и вокруг них соответствует этапам «провиденциальной» Истории.

\section{Литература}

Бент М.И., А.С. Пушкин и Г. фон Клейст: шесть фрагментов $\kappa$ сравнительной истории литературы, „Вестник Челябинского университета, Серия 2, Филология" 1999, № 1, с. 69-79.

Берковский Н.Я., Романтизм в Германии, Санкт-Петербург 2001.

Гуревич А.Я., Культура и общество средневековой Европы глазами современников (Exетpla XIII века), Москва 1989.

\footnotetext{
${ }^{22}$ См. об этом, в частности: А.И. Иваницкий, Локальные хронотопы в прозе Генриха Фон Клейста - сцены Промысла, рока и истории, [в:] Восток - Запад: пространство локального текста в литературе и фольклоре, А.И. Иваницкий, Волгоград 2019, с. 350-357.
} 
Иваницкий А.И., Локальные хронотопы в прозе Генриха фон Клейста сцены Промысла, рока и истории, [в:] Восток-Запад: пространство локального текста в литературе и фольклоре, А.И. Иваницкий, Волгоград 2019, с. 350-357.

Клейст Г. ф., Драмы. Новеллы, Москва 1969.

Мелетинский Е.М., Историческая поэтика новеллы, Москва 1990.

Михайлов А.В., Вводная часть доклада "Генрих фон Клейст и проблемы романтизма", [в:] Обратный перевод, А.В. Михайлов, Москва 2000, с. $34-45$.

Немецкая романтическая повесть, Тт. 1-2, Ленинград 1935.

Gaderer R., "Michael Kohlhaas" (1808/10): Schriftverkehr - Burokratie Querulanz, "Zeittschrift fur deutsche Philologie" 2011, Band 130, Heft 4, S. 531-544.

Girard R., Mythos und Gegenmythos. Zu Kleists 'Das Erdbeben in Chili', [in:] Positionen der Literaturwissenschaft: Acht Modellanalysen am Beispiel von Kleist "Das Erdbeben in Chili", Muenchen 1985, S. 130-148.

Hamacher W., Das Beben der Darstellung, [in:] Positionen der Literaturwissenschaft: Acht Modellanalysen am Beispiel von Kleist "Das Erdbeben in Chili", Muenchen 1985, S. 149-173.

Huff St., Kleist and Expectant Virgins: The Meaning of ' $O$ ' in "Die Marquise von O...", "Journal of English and Germanic Philology" 1982, № 81, 3, Pp. 367375 .

Kittler Fr., Ein Erdbeben in Chili und Preussen, [in:] Positionen der Literaturwissenschaft: Acht Modellanalysen am Beispiel von Kleist "Das Erdbeben in Chili", Muenchen 1985, S. 24-38.

Koch F., Heinrich von Kleist. Bewusstsein und Wirklichkeit, Stuttgart 1958.

Kreutzer H.J., "... aber niemand bedarf ihrer...", in: Holderlin-Jahrbuch, Band 26 (1989), S. 60-73.

Loch F., Kleist, Leipzig 1978.

Maurer K.-H., Gerechtigkeit zwischen Differenz und Identitaet in Heinrich von Kleists "Michael Kohlhaas", "Deutsche Vierteljahrsschrift fur Literaturwiss. u. Geistesgeschichte" 2001, Jg. 75, Heft 1, S. 123-149.

Schneider H.J., Der Zusammensturz des Allgemeinen, [in:] Positionen der Literaturwissenschaft: Acht Modellanalysen am Beispiel von Kleist "Das Erdbeben in Chili", Muenchen 1985, S. 110-129.

Stephens A., Kleist - Sprache und Gewalt, 1 Aufl., Freiburg im Breisgau 1999.

Stierle K.-H., Das Beben des Bewusstseins / Die narrative Struktur von Kleists 'Das Erdbeben in Chili, [in:] Positionen der Literaturwissenschaft: Acht Modellanalysen am Beispiel von Kleist "Das Erdbeben in Chili", Muenchen 1985, S. 54-68. 
Wellbery D.E., Das Beben des Bewusstseins / Die narrative Struktur von Kleists 'Das Erdbeben in Chili', [in:] Positionen der Literaturwissenschaft: Acht Modellanalysen am Beispiel von Kleist "Das Erdbeben in Chili", Muenchen 1985 , S. $69-87$.

Wichmann Th., Heinrich von Kleist, Stuttgart 1988.

\section{References}

Bent M.I., A.S. Pushkin i G. fon Klejst: shest' fragmentov $k$ sravnitel'noj istorii literatury, "Vestnik CHelyabinskogo universiteta, Seriya 2, Filologiya" 1999, № 1 , s. 69-79.

Berkovskij N.YA., Romantizm v Germanii, Sankt-Peterburg 2001.

Gaderer R., "Michael Kohlhaas" (1808/10): Schriftverkehr - Burokratie Querulanz, "Zeittschrift fur deutsche Philologie" 2011, Band 130, Heft 4, S. 531-544.

Girard R., Mythos und Gegenmythos. Zu Kleists 'Das Erdbeben in Chili', [in:] Positionen der Literaturwissenschaft: Acht Modellanalysen am Beispiel von Kleist "Das Erdbeben in Chili", Muenchen 1985, S. 130-148.

Gurevich A.YA., Kul'tura $i$ obshchestvo srednevekovoj Evropy glazami sovremennikov (Exempla XIII veka), Moskva 1989.

Hamacher W., Das Beben der Darstellung, [in:] Positionen der Literaturwissenschaft: Acht Modellanalysen am Beispiel von Kleist "Das Erdbeben in Chili", Muenchen 1985, S. 149-173.

Huff St., Kleist and Expectant Virgins: The Meaning of ' $O$ ' in "Die Marquise von O...”, “Journal of English and Germanic Philology" 1982, № 81, 3, Pp. 367375.

Ivanickij A.I., Lokal'nye hronotopy v proze Genriha fon Klejsta - sceny Promysla, roka $i$ istorii, [v:] Vostok - Zapad: prostranstvo lokal'nogo teksta $v$ literature ifol'klore, Ivanickij A.I., Volgograd 2019, s. 350-357.

Kittler Fr., Ein Erdbeben in Chili und Preussen, [in:] Positionen der Literaturwissenschaft: Acht Modellanalysen am Beispiel von Kleist "Das Erdbeben in Chili", Muenchen 1985, S. 24-38.

Klejst G. f., Dramy. Novelly, Moskva 1969.

Koch F., Heinrich von Kleist. Bewusstsein und Wirklichkeit, Stuttgart 1958.

Kreutzer H.J., "... aber niemand bedarf ihrer...", in: Holderlin-Jahrbuch, Band 26 (1989), S. 60-73.

Loch F., Kleist, Leipzig 1978.

Maurer K.-H., Gerechtigkeit zwischen Differenz und Identitaet in Heinrich von Kleists "Michael Kohlhaas", "Deutsche Vierteljahrsschrift fur Literaturwiss. u. Geistesgeschichte" 2001, Jg. 75, Heft 1, S. 123-149.

Meletinskij E.M., Istoricheskaya poetika novelly, Moskva 1990.

Mihajlov A.V., Vvodnaya chast' doklada "Genrih fon Klejst i problemy romantizma", [v:] Obratnyj perevod, Mihajlov A.V., Moskva 2000, s. 34-45. 
Nemeckaya romanticheskaya povest', Tt. 1-2, Leningrad 1935.

Schneider H.J., Der Zusammensturz des Allgemeinen, [in:] Positionen der Literaturwissenschaft: Acht Modellanalysen am Beispiel von Kleist "Das Erdbeben in Chili", Muenchen 1985, S. 110-129.

Stephens A., Kleist - Sprache und Gewalt, 1 Aufl., Freiburg im Breisgau 1999.

Stierle K.-H., Das Beben des Bewusstseins / Die narrative Struktur von Kleists 'Das Erdbeben in Chili', [in:] Positionen der Literaturwissenschaft: Acht Modellanalysen am Beispiel von Kleist "Das Erdbeben in Chili", Muenchen 1985, S. 54-68.

Wellbery D.E., Das Beben des Bewusstseins / Die narrative Struktur von Kleists 'Das Erdbeben in Chili', [in:] Positionen der Literaturwissenschaft: Acht Modellanalysen am Beispiel von Kleist "Das Erdbeben in Chili", Muenchen 1985, S. $69-87$.

Wichmann Th., Heinrich von Kleist, Stuttgart 1988. 